\section{Living with the Neanderthals}

\author{
Darwin's Children: Evolution Has \\ Changed the Face of the World \\ by Greg Bear \\ HarperCollins: 2003.400 pp. $£ 17.99$ \\ Del Rey: 2003. 368 pp. $\$ 24.95$

\section{Michael A. Goldman}

Science, the ultimate arbiter of truth, is still stained by the imperfections of human nature. We sometimes think we have all the answers. But the preposterous ideas of yesterday are the unshakeable dogmas of today, and the ancient superstitions of tomorrow. Science is driven by politics, and politics by fear. Greg Bear's latest novel, Darwin's Children, grapples with the biases of our society, and the machinations of science, politics and science policy, in the face of its most formidable challenge for more than 25,000 years: the next step in human evolution. Today's wild speculations might not make it into tomorrow's textbooks, but Bear's ability to tell a good story is surpassed only by his enthusiasm for the advancing edge of molecular biology.

In Darwin's Radio, the forerunner to Darwin's Children, fictional molecular biologist Kaye Lang and anthropologist Mitch Rafelson were at the epicentre of a radical new view of 'human' genetics and evolution. Human endogenous retroviruses (HERVs) had suddenly mobilized and were wreaking havoc on the newly sequenced genome. Herod's plague, later dubbed SHEVA (for scattered human endogenous retrovirus activation), infected pregnant women, causing spontaneous abortion of a fetus and subsequent development of a 'daughter' zygote that had undergone virus-directed mutation. The children born of SHEVA pregnancies represented the next step in human evolution. They communicated using a combination of double-speak, olfaction and skin freckling.

The plague had been seen at least twice before - once at the scene of a massacre of pregnant women in the recent past, and once in the Ice Age, when a late-stage Neanderthal couple gave birth to an early-stage modern human. The mobilization of the endogenous retroviruses, it seemed, was a response to stress that shuffled the genome in a relatively organized way, and potentiated speciation, or at least subspeciation. Predictably, Rafelson and Lang had trouble convincing the scientific establishment that we weren't just dealing with a standard epidemic, but a natural and desirable advance.

At the opening of Darwin's Children, modern society isn't ready to share its bounty with a new race of human, or a new species of hominid. The 2.5 million surviving 'virus children', or Shivites, are mostly confined to special schools or concentration camps. New branches of law enforcement and public health, enjoying the federal budget dividends of fear, have been established to deal with the problem. Rafelson and Lang themselves had a SHEVA child, Stella Nova, whom they raised out of the grip of the government's Emergency Action directives, and did their loving best to conquer a quantum generation gap. SHEVA dominates the political scene, shifting our way of life. Habeas corpus is suspended for renegade Shivites, as it was in the aftermath of the September 2001 terrorist attacks for Middle Eastern men suspected of terrorist links. The world is gripped by a dread of nature, much as we are today by diseases such as SARS or AIDS. Viruses jump species barriers as humans tamper with the balance of nature.

In weaving his story, Bear takes us through dozens of enticing didactic excursions filled with speculation about everything from molecular biology to God. Writes Kaye Lang: "The role of SHEVA in the production of a new subspecies is but one function... They are mediators and messengers between cells, ferrying genes and coded data around many parts of the body, and even between individuals... They are like original sin.” Peripheral ideas abound, but not so very long ago the concept of a simple molecule such as DNA being an information-carrying instrument was inconceivable.

The epiphany scenes, in which superheroine Lang meets an all-loving, all-forgiving "caller", will shock the most die-hard sciencefiction fans, and stun the average Nature reader. Bear does an admirable job of trying to square religious beliefs and scientific reason when functional magnetic resonance imaging is used to see what a revelation looks like. And he never takes us quite to the brink of a miracle, stating emphatically in an epilogue that he isn't advocating special creation or God-directed evolution. In short, he reminds us that the mystic experiences that people have are neurological events as real as any other perception, and suggests that they might just be manifestations of a higher organic (as opposed to spiritual) existence.

Like all the best science fiction, Darwin's Children is a medium for telling the public about science. Through one of his characters, Bear pleads for biologists to write clearly: "Don't they realize how important it is to get the word out to everybody?"

Bear makes a few mistakes of definition, going beyond the studied speculation expected in a hard science-fiction novel. For instance, he makes reference to the odd karyotype of a virus child as " $52 \mathrm{xx}$ " - convention would have it written as " $(52, \mathrm{XX})$ ". He calls this a polyploid number, but it isn't a multiple of the haploid human chromosome number of 23 , so really it should be 'aneuploid'. Bear incorporates the new 'fact' that humans have some 30,000 genes into his definition of 'genome', accepting it as canon, but he rejects the less controversial (albeit possibly incorrect) 'fact' that we are not descended from the Neanderthals.

Although Darwin's Children works well on its own, readers who skip Darwin's Radio and plunge straight in will miss some of the intense excitement of mystery and discovery. Darwin's Children is more a chronicle of the new humanity's first attempt to share the planet with its forebears, and contains a lot of good expository prose about the

\section{Seeing the light}

Light may be the life force of fine art, but light itself takes centre stage in Hiro Yamagata's imposing exhibition in the Japanese seaport of Yokohama.

In a display co-hosted by NASA, a pair of 20-metre cubes covered with holographic panels (right) make art out of sunlight, refracting its beams to shower coloured rays over surrounding buildings.

Nearby, Yamagata's dizzying NGC6093 installation, which is named after a dense star cluster in the constellation Scorpio, consists of an enclosed room with holographic walls and floor, filled with dangling mirror cubes. Rotating lasers bounce beams through this maze of light sources. In one of the most beautiful - and unintentional - effects, green light catches the nylon that is used to hang the mirror cubes, and pours down like electric rain.

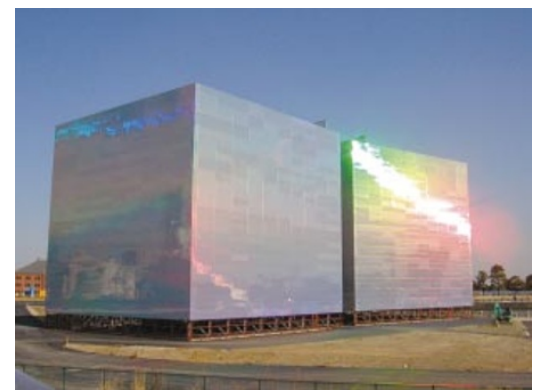

Yamagata says that his laser shows mark a deliberate attempt to distance himself from the commercial paintings for which he is best known in Japan.

David Cyranoski

"The World of Hiro Yamagata and NASA" can be seen at Yokohama, Japan, until the end of September.

www.hiroyamagata.net 
virus children's relationship to their world.

Bear's two Darwin novels were not written just to entertain. He also seeks to teach readers about science, to highlight our utilitarian politics and our inability to get along with each other, and to provide a quasirational basis for theology and morality. He advances a world view in which we are all part of the vast neural network of life, cutting across ethnic borders, species divides and the chasms between taxonomic kingdoms, in balance, and in two-way communication, with the ecosystem. Bear might be off the mark, or he might just be anticipating the next giant leap in our understanding of evolution and ourselves.

Michael A. Goldman is in the Department of

Biology, San Francisco State University,

San Francisco, California 94132-1722, USA.

\section{The last of its kind?}

\section{Pheidole in the New World: A Dominant, Hyperdiverse \\ Ant Genus}

by Edward O. Wilson

Harvard University Press: 2003. 818 pp.

$\$ 125.00, \mathfrak{f} 83.50, € 125.00$

\section{Donat Agosti}

"Everything goes." Philosopher Paul Feyerabend's statement of anarchy in scientific method - that you can research however you like - might well hold for taxonomic monographing. The field is plagued by an increasing shortage of specialists, despite the ever-growing pressure to complete the 'catalogue of life' with descriptions of new species and revisions of known species. Pheidole in the New World makes a sizeable advance, describing 624 species of ant, of which 337 are new to science. It was written by Harvard University biologist E. O. Wilson, one of the world's leading biologists and environmentalists, and published by Harvard University Press, which has a much higher profile than most of the 500plus journals in which ant descriptions usually appear.

This important book is modelled on the highly successful Peterson's field guides. Each species is given one page, of which half is covered by lavish line drawings with very helpful indicators marking the diagnostic characters. The rest of the page contains a short description (including a series of standard measurements), a handy indication of closely related species, a summary of key biological features and the distribution range. Unfortunately, details of the biological materials examined are either missing or incomplete.

The book's introduction includes some notes on the ecology of the genus Pheidole, some generalities on hyperdiversity, an illus-

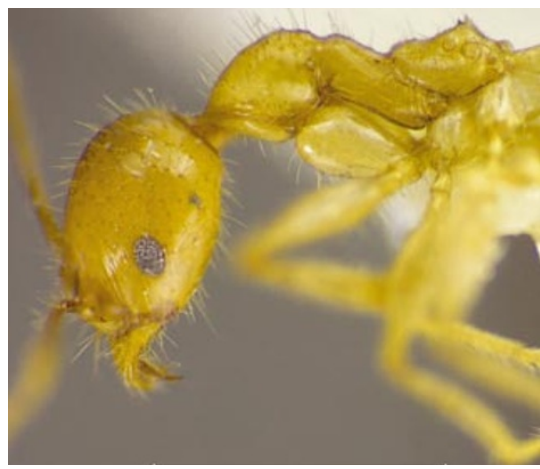

available online this autumn, providing an enormous free resource. Wilson's Pheidole in the New World will not be part of this system, as the book is copyrighted: as a result, apart from the unprotected nomenclatorial information and links to those images available at Harvard's online Primary Type Specimen Database, its 624 descriptions cannot be readily integrated into the worldwide biodiversity knowledge base. This raises serious issues about an academic publisher's obligations to make biodiversity data freely available for non-commercial research, education and conservation.

The inaccessibility of published records
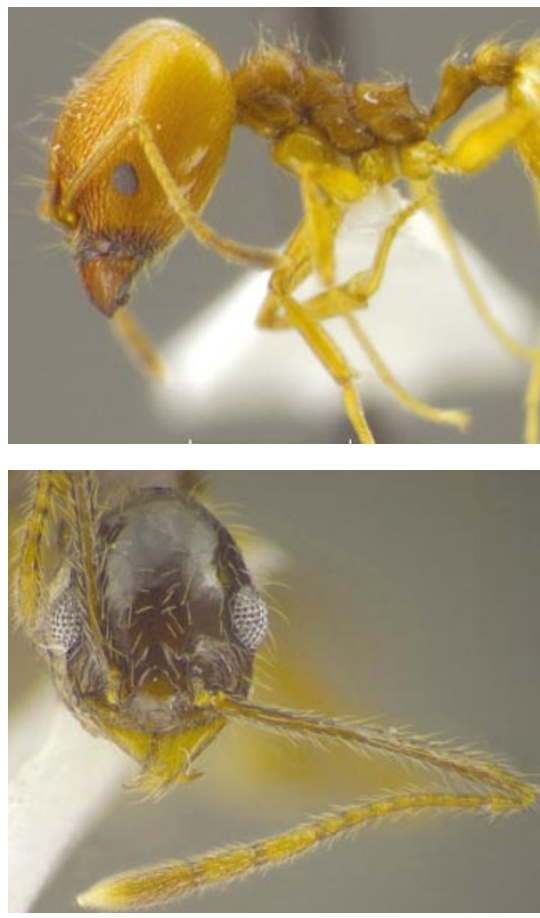

Adding ants: Pheidole subsphaerica (top),

$P$. cursor and P. lupus are three of 337 new ant species described by E. O. Wilson.

trated glossary, and an uninspiring, unillustrated key to species. The pièce de résistance is an accompanying CD-ROM, which comprises fantastic colour images of about half of the species and a simple search engine.

Ant taxonomy is at a vibrant stage of development, with more than 130 active scientific contributors, all but two of whom are connected over the Internet. Since the last catalogue of the world's ants was published - Barry Bolton's A New General Catalogue of the Ants of the World (Harvard University Press, 1995) - 1,630 new ant species, including those in this book, have been described. A database (www.antbase.org) with a single web page for each species provides links to an increasing number of extraordinary websites, organized by region (such as www.antweb.org) or theme (GenBank).

The entire 3,500 taxonomic publications covering the non-copyrighted systematics of the 11,574 known species of ant will be frustrates efforts to compile lists of the world's living species, and to develop the next generation of tools and data repositories that can be seamlessly woven into systems such as GenBank, biodiversity monitoring systems, or the fledgling Global Biodiversity Information Facility. Records are hidden in thousands of journals and books, and access to new work is increasingly restricted by an ever more proprietary copyright environment. Money aside, even password protection impedes the building of information networks.

Most of the species described in Pheidole in the New World are based on material collected in the tropics, where most of the world's species live and vanish. The Convention on Biological Diversity, sadly still not ratified by the United States, calls for the exchange of scientific information and repatriation of data to the place of origin. Selling expensive books doesn't aid this process.

Wilson isn't just a taxonomist - he is a prominent biologist and an outspoken environmentalist. His style of science and his involvement with conservation set precedents far beyond taxonomy. He espouses the development of an Internet-based 'encyclopaedia of life', stresses the virtue of the biodiversity commons - a movement to make biodiversity information freely accessible for non-commercial use - and would like to see taxonomy follow the DNA revolution (Trends Ecol. Evol. 18, 77-80; 2003), but his book on Pheidole doesn't reflect these ideals.

In these days of biodiversity crises, taxonomy isn't just a science where "everything goes". It has the potential to play a pivotal role not enough to talk about the biodiversity crisis; action is required. It is a pity that Wilson, with his ingenuity and access to resources, did not grasp the opportunity to present these important data in a more novel and useful way, but instead preferred to produce, in his own words, the "last of its kind": another visually appealing monograph. Donat Agosti is in the Division of Invertebrate Zoology, American Museum of Natural History, Central Park West at 79th Street, New York, New York 10024-5192, USA. in quantifying changes in biodiversity. It is 